\title{
High-pressure lattice-dynamics of $\mathrm{NdVO}_{4}$
}

V. Panchal ${ }^{1}$, D. Errandonea ${ }^{2} \uparrow$, F.J. Manjón ${ }^{3}$, A. Muñoz ${ }^{4}$, P. Rodríguez-Hernández ${ }^{4}$, S.N. Achary $^{5}$, and A.K. Tyagi ${ }^{5}$

${ }^{1}$ Royal College of Arts, Science and Commerce, Mira Road, Mumbai 401 107, India

${ }^{2}$ Departamento de Física Aplicada-ICMUV, MALTA Consolider Team, Universidad de Valencia, Edificio de Investigación, C/Dr. Moliner 50, 46100 Burjassot (Valencia), Spain

${ }^{3}$ Instituto de Diseño para la Fabricación y Producción Automatizada, MALTA Consolider Team, Universidad Politécnica de Valencia, Camino de Vera s/n, 46022 Valencia, Spain

${ }^{4}$ Departamento de Física Fundamental II, Instituto de Materiales y Nanotecnología, MALTA Consolider Team, Universidad de La Laguna, La Laguna 38205, Tenerife, Spain

${ }^{5}$ Chemistry Division, Bhabha Atomic Research Centre, Trombay, Mumbai 400085, India

\begin{abstract}
High-pressure Raman-scattering measurements and ab initio calculations on $\mathrm{NdVO}_{4}$ have been carried out up to $30 \mathrm{GPa}$. Our combined experimental and theoretical study confirms that beyond $5.9 \mathrm{GPa} \mathrm{NdVO}_{4}$ undergoes an irreversible zircon to monazite transition. The coexistence of zircon and monazite phases is experimentally observed up to $\sim 8 \mathrm{GPa}$ (which agrees with the theoretical transition pressure), stabilizing the monazite phase as a single phase around $10 \mathrm{GPa}$. Calculations additionally predict the existence of a second high-pressure phase transition at $12.4 \mathrm{GPa}$. This reversible phase transition has been experimentally observed beyond 18.1 $\mathrm{GPa}$ and remains stable up to $30 \mathrm{GPa}$. The post-monazite phase is predicted to have a monoclinic structure isomorphic to the $\mathrm{BaWO}_{4}$-II type structure. The calculated structure for the three polymorphs of $\mathrm{NdVO}_{4}$ is reported and the pressure dependence of their Raman modes is discussed.
\end{abstract}

Keywords: Raman spectroscopy, Ab initio calculations, High pressure, Phase transitions †Corresponding author; email: daniel.errandonea@uv.es 


\section{Introduction}

The study of zircon-structured orthovanadates is important in the fields of geology and materials science. They are refractory materials, can withstand high pressures and temperatures, and generally show low thermal expansion, being useful for the ceramic industry [1]. In addition, orthovanadates found applications in thermophosphors, scintillators, photocatalysts, cathodoluminescent materials, and in lithium ion batteries [2, 3]. These materials are also used as laser-host materials when doped with trivalent impurities due to their high optical conversion efficiency, high birefringence and good thermal conductivity [4]. Recently, they have been used for the development of dual-wavelength lasers [5]. Furthermore, they can be also used to immobilize nuclear waste [6].

Rare-earth $A \mathrm{VO}_{4}$ orthovanadates $(A=\mathrm{Sc}, \mathrm{Y}, \mathrm{La}-\mathrm{Lu})$ mostly crystallize in the tetragonal zircon-type structure (space group I4/amd) [7], although it has been found that a few orthovanadates (e.g. $\mathrm{LaVO}_{4}$ ) crystallize in the monazite structure (space group $\mathrm{P} 2{ }_{1} / \mathrm{n}$ ), depending on the synthesis conditions and cationic size [8]. Another structure which is closely related to zircon and monazite structures is the scheelite (space group $\mathrm{I}_{1} / \mathrm{a}$ ) structure. All these three structures have in common a sequence of chains of alternating polyhedral units and planes of closed packed $A$ cations. In particular, $\mathrm{NdVO}_{4}$ crystallizes in the tetragonal zircon structure and can be viewed as alternating edge-sharing $\mathrm{NdO}_{8}$ dodecahedra and $\mathrm{VO}_{4}$ tetrahedra forming chains parallel to the $c$-axis.

Recent investigations on orthovanadates and related ternary oxides implied a strong correlation of $r_{A} / r_{O}$ and $r_{V} / r_{O}$ cation-anion radius ratio on high-pressure (HP) structural phase transitions [9]. In general, orthovanadate compounds show zircon-to-scheelite [10 - 16] or zircon-to-monazite [17 -19] structural phase transitions. Some works also report post-scheelite 
and post-monazite transitions [20,21]. In addition, the compressibility and HP Raman scattering (RS) of orthovanadates have been recently explored [22 - 26]. In spite of the attention devoted to the HP study of $A \mathrm{VO}_{4}$ orthovanadates, $\mathrm{NdVO}_{4}$ is one of the less studied members of this family. Earlier HP optical-absorption measurements on $\mathrm{NdVO}_{4}$ found a sharp drop in energy band-gap $\left(\mathrm{E}_{\mathrm{g}}\right)$ from 3.72 to $3.30 \mathrm{eV}$ at $\sim 6 \mathrm{GPa}$. At $11.4 \mathrm{GPa}$ another discontinuity in $\mathrm{E}_{\mathrm{g}}$ was detected, indicating a second phase transition around this pressure [27]. The first drop was attributed to a zircon to monazite transition around $6.5 \mathrm{GPa}$ in recent $\mathrm{HP}$ x-ray diffraction (XRD) measurements [18]; however, the second pressure-induced phase transition was not verified in that HP-XRD study up to $12 \mathrm{GPa}$. Here we report a combined experimental and theoretical study of HP-RS measurements and $a b$ initio calculations to improve the understanding the nature of phase transitions in $\mathrm{NdVO}_{4}$.

\section{Experimental details}

$\mathrm{NdVO}_{4}$ was prepared by solid-state reaction of appropriate amounts of pre-dried $\mathrm{Nd}_{2} \mathrm{O}_{3}$ (Indian Rare Earth Ltd. 99\%) and $\mathrm{V}_{2} \mathrm{O}_{5}$ (Alfa-Aesar 99\%). Homogeneous mixtures of the reactants were pelletized and heated at $800{ }^{\circ} \mathrm{C}$ for $24 \mathrm{~h}$ and then cooled to ambient temperature. Further, the pellets were reground and heated again at $1100{ }^{\circ} \mathrm{C}$ for $24 \mathrm{~h}$. X-ray diffraction measurements at ambient conditions using $\mathrm{Cu} \mathrm{K}$ radiation $(\lambda=1.5418 \AA)$ confirmed a single phase with the zircon structure and $a=7.334(1) \AA$ and $c=6.436(1) \AA$, which are in very good agreement with the literature [28]. For HP-RS measurements, we used a cylindrical piece of $\mathrm{NdVO}_{4}(40 \mu \mathrm{m}$ in diameter and $10 \mu \mathrm{m}$ thick). This sample and a $2-\mu \mathrm{m}$ diameter ruby ball were loaded in a diamond-anvil cell inside a pre-indented Inconel gasket with a thickness of $40 \mu \mathrm{m}$ and a $200-\mu \mathrm{m}$ diameter hole. A 16:3:1 methanol-ethanol-water mixture was used as pressuretransmitting medium [29, 30]. The pressure was determined by monitoring the shift in ruby 
fluorescence lines [31]. Special caution was taken to avoid sample bridging between diamonds [32]. HP Raman measurements were performed in the backscattering geometry using $632.8 \mathrm{~nm}$ HeNe laser with a power of $10 \mathrm{~mW}$ and a Horiba Jobin Yvon LabRAM high-resolution UV microspectrometer in combination with a thermoelectric-cooled multichannel CCD detector with spectral resolution below $2 \mathrm{~cm}^{-1}$.

\section{Theoretical method and computational details}

$A b$ initio calculations have been performed within the density-functional theory (DFT) framework as implemented in the Vienna ab initio simulation package (VASP) [33]. The set of plane waves employed extended up to a kinetic energy cutoff of $520 \mathrm{eV}$. Such a large cutoff was required to achieve highly converged results within the projector-augmented-wave (PAW) scheme [34]. The exchange-correlation energy was taken in the generalized-gradient approximation (GGA) with the Perdew-Burke-Ernzerhof (PBE) prescription [35]. We used dense special point grids appropriate to each structure considered to sample the Brillouin zone (BZ), thus ensuring a high convergence of 1-2 meV per formula unit in the total energy as well as an accurate calculation of the forces on the atoms. At selected volumes, the structures were fully relaxed to their optimized configurations through the calculation of the forces on atoms and the stress tensor [36]. In the optimized configuration, the forces were smaller than $0.005 \mathrm{eV} / \AA$, and the deviation of the stress tensor from a diagonal hydrostatic form was less than $0.1 \mathrm{GPa}$. Lattice-dynamic calculations of the phonon modes were performed at the zone center ( $\Gamma$ point) of the BZ. We used the small-displacement method which has been shown to properly work to study phonons under compression [37-39]. These calculations also provide information about the symmetry of the modes and their polarization vectors, and allowed us to identify the irreducible representations and the character of the phonon modes at the $\Gamma$ point. 


\section{Results}

\section{A. Zircon structured $\mathrm{NdVO}_{4}$}

As regards the structural properties of zircon-type $\mathrm{NdVO}_{4}$, our $a b$ initio calculations find that the tetragonal zircon is the most stable phase of $\mathrm{NdVO}_{4}$ in agreement with previous $\mathrm{XRD}$ experiments [18]. This is shown in Fig. 1 where we represent the enthalpy versus pressure for different phases of interest. According with our calculations, at zero pressure and zero temperature, the lattice parameters of the zircon structure of $\mathrm{NdVO}_{4}$ are: $a=7.4311 \AA$ and $c=$ $6.4739 \AA$ A. For the oxygen position, the only one in general position by symmetry, we got $(0$, $0.42964,0.20493)$. These calculated lattice and atomic parameters agree well with those obtained for the zircon structure of $\mathrm{NdVO}_{4}$ from a full-profile Rietveld structure analysis of neutron powder-diffraction data [28]. As expected, our calculations overestimate the unit-cell parameters, but only by $1 \%$. We have also obtained the pressure dependence of the unit-cell volume in the pressure range of stability of the zircon structure. By fitting this dependence with a third-order Birch-Murnaghan equation of state (EOS) [40], we determined the ambient pressure volume, $\mathrm{V}_{0}$ $=357.50 \AA^{3}$, bulk modulus, $\mathrm{B}_{0}=124.2 \mathrm{GPa}$, and its pressure derivative, $\mathrm{B}_{0}{ }^{\prime}=3.66$. While $\mathrm{B}_{0}{ }^{\prime}$ and $\mathrm{V}_{0}$ agrees well with experiments, within the overestimation of the volume expected in DFT calculations, the calculated $\mathrm{B}_{0}$ is $10 \%$ smaller than the experimental value [18]. Nevertheless, the calculated $\mathrm{B}_{0}$ and $\mathrm{B}_{0}$ ' lie within the $3 \sigma$ confidence-level ellipse [40] determined from experiments [18]. Therefore, we can conclude that $a b$ initio calculations provide a good description of the compression of the zircon structure.

As regards the vibrational properties of zircon-type $\mathrm{NdVO}_{4}$, group theory predicts 12 Raman-active modes at the center of the $\mathrm{BZ}$ with symmetries $\Gamma=2 \mathrm{~A}_{1 \mathrm{~g}}+4 \mathrm{~B}_{1 \mathrm{~g}}+\mathrm{B}_{2 \mathrm{~g}}+5 \mathrm{E}_{\mathrm{g}}[41]$. 
These modes can be further classified into internal $\left(v_{1}-v_{4}\right)$ and external (translational, $\mathrm{T}$, and rotational, $\mathrm{R}$ ) modes of $\mathrm{VO}_{4}$ units as follows,

$$
\Gamma=A_{1 g}\left(v_{1}, v_{2}\right)+B_{1 g}\left(2 T, v_{3}, v_{4}\right)+B_{2 g}\left(v_{2}\right)+E_{g}\left(2 T, R, v_{3}, v_{4}\right) .
$$

Regarding the Raman spectra measured under compression, HP-RS spectra of zircon-type $\mathrm{NdVO}_{4}$ at selected pressures are shown in Fig. 2(a). Eleven Raman-active modes are clearly discernable at ambient conditions out of the twelve predicted ones for zircon-type $\mathrm{NdVO}_{4}$ so they can be clearly assigned to the zircon structure up to $4.9 \mathrm{GPa}$. In fact, we have followed under compression the eleven Raman-active modes up to this pressure. The only change observed is the gradual shift of the phonon frequencies as pressure increase, a typical consequence of the change of interatomic distances.

The pressure dependence of Raman-active mode frequencies in the zircon phase is plotted in Fig. 2(b) with solid circles (experiments) and lines (calculations). Most Raman modes harden under compression, but there are two modes that have a distinctive behavior. These are the external $\mathrm{T}\left(\mathrm{E}_{\mathrm{g}}\right)$ mode at $113 \mathrm{~cm}^{-1}$, which shows very small pressure coefficient and the internal $v_{2}\left(B_{2 g}\right)$ mode at $260 \mathrm{~cm}^{-1}$, which shows a negative pressure coefficient. In addition, we found that there are two pairs of modes which gradually merge under compression due to their different pressure dependence. These are the modes at 243.1 and $260.9 \mathrm{~cm}^{-1}$ and at 373.4 and $381.9 \mathrm{~cm}^{-1}$ at ambient pressure. The symmetry assignment for the experimental Raman-active modes along with their experimental and calculated frequencies and pressure coefficients are summarized in Table 1. It must be noted that the pressure coefficients of all the Raman modes are comparable with other orthovanadates $[10,19,22,24,26]$. In order to complete the description of the HP behavior of the Raman-active modes of zircon-type $\mathrm{NdVO}_{4}$ in Table 1 we include the mode Grüneisen parameters, $\gamma=\left(\mathrm{B}_{0} / \omega_{0}\right)(\mathrm{d} \omega / \mathrm{dP})$, where $\mathrm{B}_{0}=148 \mathrm{GPa}$ is the bulk modulus [18]. These 
parameters are useful to estimate the pressure dependence of thermodynamic, elastic, and transport properties.

The symmetry assignment for the Raman-active modes has been performed in accordance with our lattice dynamics calculations and with previous polarized Raman studies [41, 42]. The agreement between experiments and calculations is quite good. The difference among the measured and calculated wavenumbers $(\omega)$ is smaller than $4 \%$ for all the measured modes. When comparing the pressure coefficients $(\mathrm{d} \omega / \mathrm{dP})$ we observe a similar agreement. In only one mode, the lowest frequency mode, the calculated pressure coefficient is considerable larger than the experimental coefficient.

Taking into account the good agreement between our experimental and theoretical frequencies and pressure coefficients it was rather easy to make a tentative assignment of the symmetry of the Raman-active modes experimentally observed. In this sense, the highest frequency Raman mode, the most intense mode, is the symmetric-stretching internal mode $v_{1}\left(\mathrm{~A}_{1 \mathrm{~g}}\right)$, observed at $871 \mathrm{~cm}^{-1}$ at ambient pressure. There are also two other high-frequency modes, these are the two asymmetric-stretching modes $v_{3}\left(E_{g}\right)$ and $v_{3}\left(B_{1 g}\right)$ recorded at 808 and $794 \mathrm{~cm}^{-1}$, respectively. The rest of the modes are below $475 \mathrm{~cm}^{-1}$ and correspond to either bending modes of the $\mathrm{VO}_{4}$ unit or to external (translational and rotational) modes. Regarding the bending modes of the $\mathrm{VO}_{4}$ unit, we have observed: $v_{4}\left(\mathrm{~B}_{1 \mathrm{~g}}\right)$ at $472 \mathrm{~cm}^{-1}, v_{2}\left(\mathrm{~A}_{1 \mathrm{~g}}\right)$ at $381 \mathrm{~cm}^{-1}$, $v_{4}\left(E_{g}\right)$ at $373 \mathrm{~cm}^{-1}$, and $v_{2}\left(B_{2 g}\right)$ at $260 \mathrm{~cm}^{-1}$ respectively. The translational modes correspond to the four modes found at the lowest frequencies. The only Raman mode absent is the rotational mode $\mathrm{R}\left(\mathrm{E}_{\mathrm{g}}\right)$, which is theoretically predicted at $224.6 \mathrm{~cm}^{-1}$ and has the largest pressure coefficient of all Raman-active modes. 
As regards the assignment of the symmetry of the absent Raman-active mode in rare-earth zircon-type vanadates, there is an ongoing discussion in the literature regarding why in most cases only 11 of the 12 Raman-active modes are observed and which is the non-observed mode. In most cases, the rotational mode $R\left(E_{g}\right)$ or the bending $v_{4}\left(E_{g}\right)$ mode is the one usually assumed to be not observed in these compounds [41, 42]. In this respect, HP-RS measurements can be very helpful in order to clarify which one is the absent mode. The present HP-RS measurements in $\mathrm{NdVO}_{4}$ have allowed us to find that the absent mode is the bending $v_{4}\left(\mathrm{E}_{\mathrm{g}}\right)$ mode, unlike previously assumed [41, 42]. Similarly, previous HP-RS measurements in $\mathrm{ScVO}_{4}$ and $\mathrm{TbVO}_{4}$ helped us to find that the absent mode was also the bending $v_{4}\left(E_{g}\right)$ mode $[10,26]$. However, in $\mathrm{CeVO}_{4}$ it seems that the lost mode is the bending mode $v_{2}\left(\mathrm{~A}_{1 \mathrm{~g}}\right)$ mode, which has a much larger pressure coefficient than the bending $v_{4}\left(\mathrm{E}_{\mathrm{g}}\right)$ mode [43]. In the case of $\mathrm{YbVO}_{4}, \mathrm{PrVO}_{4}$, and $\mathrm{SmVO}_{4}, \mathrm{HP}-\mathrm{RS}$ measurements were not correlated to ab initio calculations [19, 23]; however, taking into account the large pressure coefficient typical of the rotational $R\left(E_{g}\right)$ mode, and the fact that the bending $v_{4}\left(\mathrm{E}_{\mathrm{g}}\right)$ mode has a frequency near $350 \mathrm{~cm}^{-1}$; i.e., close to that of the bending $v_{2}\left(A_{1 g}\right)$ mode, we can safely conclude that the lost mode in these vanadates is also the bending $v_{4}\left(E_{g}\right)$ mode in both compounds. Moreover, since our calculations on zircon-type rare-earth orthovanadates $\mathrm{ScVO}_{4}$ [10], $\mathrm{TbVO}_{4}$ [26], $\mathrm{CeVO}_{4}$ [43], and $\mathrm{NdVO}_{4}$ (this work) have shown that both modes, one $T\left(E_{g}\right)$ and the $v_{2}\left(B_{2 g}\right)$ mode, have always a negative pressure coefficient, we can conclude that the Raman-active mode observed at $261-262 \mathrm{~cm}^{-1}$ with negative pressure coefficient in $\mathrm{YbVO}_{4}, \mathrm{PrVO}_{4}$ and $\mathrm{SmVO}_{4}$ correspond to the $\mathrm{v}_{2}\left(\mathrm{~B}_{2 \mathrm{~g}}\right)$ mode and not to the $\mathrm{T}\left(\mathrm{B}_{1 \mathrm{~g}}\right)$ as was previously assigned [19, 23]. 


\section{B. Monazite structured $\mathrm{NdVO}_{4}$}

In the structural calculations we found the occurrence of a transition from the zircon to a monazite structure at $8.5 \mathrm{GPa}$. This is consistent with the irreversible phase transition determined from XRD measurements at $6.5 \mathrm{GPa}[18]$ and with the changes observed in the optical properties of $\mathrm{NdVO}_{4}$ at $6 \mathrm{GPa}$ [27]. The XRD patterns measured for the HP phase have been assigned to a monazite-type structure [18], however a full structural refinement of the HP phase was not possible. Here we provide the complete structural description of the monazite structure (space group $\mathrm{P} 2{ }_{1} / \mathrm{n}, \mathrm{Z}=4$ ), which is given in Table 2 . The monazite phase is closely related to the zircon structure. Monazite can be viewed as being composed by alternating edge-sharing $\mathrm{NdO}_{9}$ polyhedra and $\mathrm{VO}_{4}$ tetrahedra [44]. The calculated unit-cell parameters of monazite-type $\mathrm{NdVO}_{4}$ $\left(a=6.80545 \AA, b=7.05855 \AA, c=6.54038\right.$, and $\beta=104.62^{\circ}$ at $\left.9.8 \mathrm{GPa}\right)$ are similar to those determined from XRD $\left(a=6.83 \AA, b=6.99 \AA, c=6.51 \AA\right.$, and $\beta=104.7^{\circ}$ at $\left.10.8 \mathrm{GPa}\right)$.

The zircon-monazite phase transition involves a 9\% volume collapse. From our calculations we also determined the pressure dependence of the unit-cell volume, which is described by a third-order Birch-Murnaghan EOS [40] with $\mathrm{V}_{0}=316.62 \AA^{3}, \mathrm{~B}_{0}=138.8 \mathrm{GPa}$, and $\mathrm{B}_{0}{ }^{\prime}=3.79$. The values of $\mathrm{B}_{0}$ (12\% larger than in the zircon phase) and $\mathrm{B}_{0}{ }^{\prime}$ (4\% larger than in the zircon phase) suggests that the monazite phase is less compressible than the zircon phase. A feature that has been observed in other vanadates $[20,21]$ and it is related to the increase of the packing efficiency in the monazite structure with respect to the zircon structure.

As regards the vibrational properties of monazite-type $\mathrm{NdVO}_{4}$, group theoretical calculations predict 36 vibrational Raman modes at the BZ centre with following symmetries $\Gamma=18 \mathrm{Ag}+18$ $\mathrm{B}_{\mathrm{g}}$ [45]. These modes can be further classified into internal $\left(v_{1}-v_{4}\right)$ and external (translational, $\mathrm{T}$, and rotational, $\mathrm{R}$ ) modes of $\mathrm{VO}_{4}$ units as follows, 


$$
\Gamma=\mathrm{Ag}_{\mathrm{g}}\left(6 \mathrm{~T}, 3 \mathrm{R}, v_{1}, 2 v_{2}, 3 v_{3}, 3 v_{4}\right)+\mathrm{B}_{\mathrm{g}}\left(6 \mathrm{~T}, 3 \mathrm{R}, v_{1}, 2 v_{2}, 3 v_{3}, 3 v_{4}\right)
$$

Fig. 3(a) shows the Raman spectra of $\mathrm{NdVO}_{4}$ in the monazite phase at a few representative pressures. It can be seen that at $5.9 \mathrm{GPa}$ we have observed noticeable changes in the Raman spectrum with emergence of new Raman bands, accompanied by the broadening of many Raman modes. These changes in the Raman spectra are indicative of a structural phase transition towards the lower-symmetry monoclinic monazite phase. This is in quite agreement with our calculations and previous experiments $[18,25]$. The monazite phase is predicted to be observed up to $12.4 \mathrm{GPa}$ according to our calculations and was observed up to $18.1 \mathrm{GPa}$ in our experiments [18]. The difference in the transition pressure can be related to the presence of a kinetic energy barrier between the monazite and post-monazite structures.

We have observed twenty-one Raman modes at 6.3 GPa out of thirty-six Raman modes predicted for the monazite phase of $\mathrm{NdVO}_{4}$. Similarly, in Raman scattering measurements of $\mathrm{CeVO}_{4}$, twenty-seven Raman modes were detected after the zircon-to-monazite phase transition [41]. In addition, to the Raman modes of the monazite phase, the most intense Raman mode of the zircon phase (the highest frequency mode) is observed up to $\sim 8 \mathrm{GPa}$, suggesting a phase coexistence during a $3 \mathrm{GPa}$ range.

Fig. 3(b) shows the experimental (symbols) and theoretical (lines) pressure dependence of the Raman-active modes of monazite-type $\mathrm{NdVO}_{4}$. The mode assignment of the experimentallyobserved Raman modes in monazite $\mathrm{NdVO}_{4}$ was carried out by comparing the experimental and calculated values of frequencies and pressure coefficients and is shown in Table 3 . In the table we also provide the mode Grüneisen parameters calculated assuming $\mathrm{B}_{0}=138.8 \mathrm{GPa}$. The calculated Raman frequencies and their pressure coefficients are in good agreement with our experimental ones. The Raman modes can be divided in two groups of modes, one for $\omega>750$ 
$\mathrm{cm}^{-1}$ and the other with $\omega<460 \mathrm{~cm}^{-1}$, resembling the Raman spectra of monazite-type selenates and chromates, which have been recently studied in an exhaustive way [46]. The eight highfrequency modes correspond to the internal stretching modes of the $\mathrm{VO}_{4}$ tetrahedron. This number is double the number of internal modes of the zircon phase (taking into account the double degeneration of the $v_{3}\left(E_{g}\right)$ mode in the zircon phase) because of the reduction of the crystal-symmetry of monazite, which among other things transform the regular $\mathrm{VO}_{4}$ polyhedron of the zircon phase into an irregular tetrahedron with four different $\mathrm{V}-\mathrm{O}$ distances in the monazite phase, and the doubling of the primitive unit-cell. The rest of the modes correspond to internal bending modes and external modes. As expected, the internal stretching modes are the most intense modes in our experiments.

Regarding the pressure dependence of the Raman-active modes we found that under compression most modes harden (See Fig. 3(b) and Table 3); however, we have observed a small softening of two Raman modes of $\mathrm{Ag}_{\mathrm{g}}$ symmetry at $95 \mathrm{~cm}^{-1}$ and $139 \mathrm{~cm}^{-1}$. Calculations also predict the presence of a low-frequency $\mathrm{B}_{\mathrm{g}}$ mode with a negative pressure coefficient. Similarly, three soft modes were theoretically predicted for monazite-type $\mathrm{CeVO}_{4}$ [43]. It must be stressed that the wavenumbers of these three modes never reach zero in the pressure range of stability of the monazite phase. This result indicates that they are not classical soft-modes, as those observed in a second-order displacive transition [47]. A similar weak softening of two or three modes has been previously found in monazite-type $\mathrm{CeVO}_{4}, \mathrm{PbCrO}_{4}$ and $\mathrm{LaVO}_{4}[41,48,49]$. The presence of such modes has been correlated with a weakening of the restoring force against the corresponding deformation associated to the soft phonon mode, marking probably the existence of a collective instability that tends to make the crystal structure unstable [50]. This fact is consistent with the finding of a phase transition to a post-monazite phase as we found. 


\section{Post-monazite phase}

A strong decrease of the bandgap near $11.4 \mathrm{GPa}$ was found in $\mathrm{NdVO}_{4}$ by optical-absorption experiments [27]. This change correlates with the fact that RS spectra measured from $19 \mathrm{GPa}$ to $30.8 \mathrm{GPa}$ (see Fig. 4) are quite different from those measured up to $18.1 \mathrm{GPa}$. These experimental results suggest the existence of a second phase transition in $\mathrm{NdVO}_{4}$. The existence of this second phase transition, above $12.4 \mathrm{GPa}$, is supported by our calculations, as can be seen in Fig. 1. Therefore, we think there is enough evidence to support the existence of a postmonazite phase in $\mathrm{NdVO}_{4}$. In a previous work, a tentative phase transition to the scheelite phase was proposed [27]; however, in this work we have carried out calculations for a larger number of candidate structures on the light of the Bastide's diagram [8]. Our improved calculations suggest the possibility that the post-monazite phase in $\mathrm{NdVO}_{4}$ is of $\mathrm{BaWO}_{4}$-II-type. A similar structure has been proposed as a $\mathrm{HP}$ structure in related oxides $\mathrm{BaWO}_{4}, \mathrm{PbWO}_{4}$, and $\mathrm{SrMO}_{4}$ [51 - 53]. The Raman spectra of such phases [53 - 56] have qualitative similitudes with the Raman spectrum of the post-monazite phase of $\mathrm{NdVO}_{4}$.

Details on the crystal structure of the $\mathrm{BaWO}_{4}$-II structure of $\mathrm{NdVO}_{4}$ are given in Table 4 . This structure is monoclinic (space group $\mathrm{P} 2{ }_{1} / \mathrm{n}, \mathrm{Z}=8$ ) and can be described with the same space group than monazite, however it has 8 formula units in the unit cell instead of 4 . The phase transition involves an increase of the coordination number for both $\mathrm{V}$ and $\mathrm{Nd}$ and there is a volume collapse associated to it. Its EOS is described by the following parameters: $\mathrm{V}_{0}=596.35$ $\AA^{3}, \mathrm{~B}_{0}=146.8 \mathrm{GPa}$, and $\mathrm{B}_{0}^{\prime}=3.42$. This indicates that, the post-monazite phases have slightly smaller volume compressibility than the monazite phase.

As regards the vibrational properties of the $\mathrm{BaWO}_{4}$-II-type $\mathrm{NdVO}_{4}$, group theory predicts 72 Raman-active modes $\left(36 \mathrm{~A}_{\mathrm{g}}\right.$ and $\left.36 \mathrm{~B}_{\mathrm{g}}\right)$. The number of Raman modes is double in the $\mathrm{BaWO}_{4}-\mathrm{II}$ 
phase than in monazite, despite they share the same space group, because of the double number of formula units in the primitive cell of this phase than in the monazite structure. The calculated wavenumber and pressure dependence of the different modes is given in Table 5. In contrast with the other two phases, in the $\mathrm{BaWO}_{4}$-II-type phase all pressure coefficients are positive. Another distinctive feature of the post-monazite phase is that phonons are continuously distributed from 80 to $950 \mathrm{~cm}^{-1}$. In contrast, the zircon and monazite phases have a large phonon gap between the internal stretching mode and the rest of the modes as we commented above. It is possible that, due to this large number of modes and because many of them are very close in frequency, a considerable broadening in the Raman spectrum on the post-monazite phase was observed. This broadening precludes us of making an accurate frequency determination of the different modes of the post-monazite phase. Therefore, from the experiments we can only state that there exist a post-monazite phase and that it has a Raman spectrum similar to that expected for a $\mathrm{BaWO}_{4}-\mathrm{II}$ structure. The calculated phonon frequencies, pressure coefficients, and the mode Grüneisen parameters (calculated using $\mathrm{B}_{0}=146.8 \mathrm{GPa}$ ) are summarized in Table 5 .

It is important to note that despite the observation of a broad band at high frequencies, makes difficult an individual analysis of the different internal modes which are very close in frequency, a general drop in the average frequency of the broad band of intense high-frequency modes on the transition from monazite-to- $\mathrm{BaWO}_{4}$-II can be observed. This drop in frequency is consistent with the increase of the $\mathrm{V}$ coordination in the $\mathrm{BaWO}_{4}$-II-type phase with respect to the monazite-type phase. Therefore, on the light of the exposed results we are confident that the second HP phase of $\mathrm{NdVO}_{4}$ is the $\mathrm{BaWO}_{4}$-II structure. Furthermore, the monazite-BaWO $\mathrm{B}_{4} \mathrm{II}$ phase transition is consistent with Bastide's diagram [8] because in some materials the monazitescheelite phase transition can be skipped and undergo a phase transition directly to a post- 
scheelite phase, as evidenced in $\mathrm{PbWO}_{4}$ and $\mathrm{BaWO}_{4}$ [50 - 53]. Additionally, monazite $\mathrm{LaVO}_{4}$ has been recently reported to undergo a monazite- $\mathrm{BaWO}_{4}$-II transition [48], which suggests that the $\mathrm{BaWO}_{4}$-II structure might be a common post-monazite phase in $A \mathrm{VO}_{4}$ vanadates if the trivalent cation has a large ionic radius ( $\mathrm{La}, \mathrm{Ce}, \mathrm{Nd}$, and $\mathrm{Pr})$.

\section{Conclusions}

Our Raman experiments and ab initio calculations on $\mathrm{NdVO}_{4}$ up to $30.8 \mathrm{GPa}$ provides evidence supporting that the low-pressure zircon phase undergo an irreversible zircon-tomonazite transition at 5.9 GPa. The symmetries of the Raman modes in the zircon and monazite phases of $\mathrm{NdVO}_{4}$ have been assigned in accordance with our lattice dynamics calculations. The pressure dependence of the different modes is discussed. In particular, both zircon and monazite phases have modes that undergo a weak softening under compression. Beyond 18.1 GPa $\mathrm{NdVO}_{4}$ undergoes a second phase transition. Our calculations predict a monazite-to- $\mathrm{BaWO}_{4}$-II phase transition. Details on the calculated crystal structure of the three polymorphs of $\mathrm{NdVO}_{4}$ are reported together with their room temperature equation of states. The calculated Raman modes for the $\mathrm{BaWO}_{4}$-II phase are also reported. The RS spectra of $\mathrm{NdVO}_{4}$ are reasonably consistent with the $\mathrm{BaWO}_{4}$-II phase. Further HP-XRD measurements, at least up to $25 \mathrm{GPa}$, are needed to fully check the $\mathrm{BaWO}_{4}-\mathrm{II}$ nature of the second $\mathrm{HP}$ phase of $\mathrm{NdVO}_{4}$.

\section{Acknowledgments}

The authors thank the financial support provided by the Spanish government MINECO under Grants No: MAT2013-46649-C4-1/2/3 and MAT2015-71070-REDC.

\section{References}

[1] S. J. Patwe, S. N. Achary, A. K. Tyagi, Lattice thermal expansion of zircon-type $\mathrm{LuPO}_{4}$ and LuVO 4 : A comparative study, American Mineral. 94 (2009) 98-104. 
[2] S. P. Shafi, M. W. Kotyk, L. M. D. Cranswick, V. K. Michaelis, S. Kroeker, and M. Bieringer, In Situ Powder X-ray Diffraction, Synthesis, and Magnetic Properties of the Defect Zircon Structure $\mathrm{ScVO}_{4-x}$, Inor. Chem. 48 (2009) 10553-10559.

[3] J. Xu, C. Hu, G. Liu, H. Liu, G. Du, Y. Zhang, Synthesis and visible-light photocatalytic activity of $\mathrm{NdVO}_{4}$ nanowires, J. Alloys Compd. 509 (2011) 7968-7972.

[4] D. Zhong, B. Teng, W. Kong, J. Li, S. Zhang, Y. Li, L. Cao, L. Yang, L. He, W. Huang, Growth, thermal and laser properties of $\mathrm{Yb}: \mathrm{Y}_{\mathrm{x}} \mathrm{Lu}_{1-\mathrm{x}} \mathrm{VO}_{4}$ mixed crystal, Mater. Chem. Phys. 160 (2015) 155-160.

[5] Z. Wu, Z. Wang, F. Zhang, Y. Liu, J. Lu, X. Xu, Optical frequency fork based on stimulated Raman scattering, J. Alloys Compd. 682 (2016) 537-542.

[6] Y. Ding, X. Lu, H. Dan, X. Shu, S. Zhang, T. Duan, Phase evolution and chemical durability of Nd-doped zircon ceramics designed to immobilize trivalent actinides, Ceram. Intern. 41(2015) 10044-10050.

[7] A. B. Garg, D. Errandonea, P. Rodriguez-Hernandez, S. Lopez-Moreno, A. Muñoz, C. Popescu, High-pressure structural behaviour of $\mathrm{HoVO}_{4}$ : combined XRD experiments and ab initio calculations, J. Phys. Condens. Matter 26 (2014) 265402.

[8] X. R. Cheng, D. J. Guo, S. Q. Feng, K. Yang, Y. Q. Wang, Y. F. Ren, Y. Song, Structure and stability of monazite- and zircon-type $\mathrm{LaVO}_{4}$ under hydrostatic pressure, Optic. Mater. 49 (2015) 32-38.

[9] D. Errandonea, F. J. Manjón, Pressure effects on the structural and electronic properties of $\mathrm{ABX}_{4}$ scintillating crystals, Prog. Mater. Sci. 53 (2008) 711-773. 
[10] V. Panchal, F. J. Manjón, D. Errandonea, P. Rodríguez Hernández, J. López-Solano, A. Muñoz, S. N. Achary, A. K. Tyagi, High-pressure study of $\mathrm{ScVO}_{4}$ by Raman scattering and $a b$ initio calculation, Phys. Rev. B 83 (2011) 064111.

[11] D. Errandonea, R. Lacomba-Perales, J. Ruiz-Fuertes, A. Segura, S. N. Achary, A. K. Tyagi, High-pressure structural investigation of several zircon-type orthovanadates, Phys. Rev. B 79 (2009) 184104.

[12] F. J. Manjón, P. Rodríguez-Hernández, A. Muñoz, A. H. Romero, D. Errandonea, Lattice dynamics of $\mathrm{YVO}_{4}$ at high pressures, Phys. Rev. B 81 (2010) 075202.

[13] R. Rao, A. B. Garg, T. Sakuntala, S. N. Achary, A. K. Tyagi, High pressure Raman scattering study on the phase stability of $\mathrm{LuVO}_{4}$, J. Solid. State Chem. 182 (2009) 1879-1883.

[14] C. Popescu, A. B. Garg, D. Errandonea, J. A. Sans, P. Rodriguez-Hernandez, S. Radescu, A. Muñoz, S. N. Achary, A. K. Tyagi, Pressure-induced phase transformation in zircon-type orthovanadate $\mathrm{SmVO}_{4}$ from experiment and theory, J. Phys. Condens. Matter 28 (2016) 035402.

[15] A. B. Garg, D. Errandonea, High-pressure powder x-ray diffraction study of $\mathrm{EuVO}_{4}$, J. Solid. State Chem. 226 (2015) 147-153.

[16] Z. Huang, L. Zhang, W. Pan, Physical properties of zircon and scheelite lutetium orthovanadate: Experiment and first-principles calculation, J. Solid. State Chem. 205 (2013) 97-103.

[17] H. Yuan, K. Wang, C. Wang, B. Zhou, K. Yang, J. Liu, B. Zou, Pressure-Induced Phase Transformations of Zircon-Type $\mathrm{LaVO}_{4}$ Nanorods, J. Phys. Chem. C 119 (2015) 8364-8372.

[18] D. Errandonea, C. Popescu, S. N. Achary, A. K. Tyagi, M. Bettinelli, In situ high-pressure synchrotron X-ray diffraction study of the structural stability in $\mathrm{NdVO}_{4}$ and $\mathrm{LaVO}_{4}$, Mat. Res. Bull. 50 (2014) 279-284. 
[19] D. Errandonea, S.N. Achary, J. Pellicer-Porres, A.K. Tyagi, Pressure-Induced Transformations in $\mathrm{PrVO}_{4}$ and $\mathrm{SmVO}_{4}$ and Isolation of High-Pressure Metastable Phases, Inorg. Chem. 52 (2013) 5464-5469.

[20] D. Errandonea, R.S. Kumar, S.N. Achary, A.K. Tyagi, In situ high-pressure synchrotron Xray diffraction study of $\mathrm{CeVO}_{4}$ and $\mathrm{TbVO}_{4}$ up to $50 \mathrm{GPa}$, Phys. Rev. B 84 (2011) 224121.

[21] A. B. Garg, K. V. Shanavas, B. N. Wani, S. M. Sharma, Phase transition and possible metallization in $\mathrm{CeVO}_{4}$ under pressure, J. Solid State Chem. 203 (2013) 273.

[22] W. Paszkowicz, J. Lopez-Solano, P. Piszora, B. Bojanowski, A. Mujica, A. Muñoz, Y. Cerenius, S. Carlson, H. Dabkowska, Equation of state and electronic properties of EuVO $\mathrm{E}_{4} \mathrm{~A}$ high-pressure experimental and computational study, J. Alloys Compd. 648 (2015) 1005-1016.

[23] A. B. Garg, R. Rao, T. Sakuntala, B. N. Wani, V. Vijayakumar, Phase stability of $\mathrm{YbVO}_{4}$ under pressure: In situ X-ray and Raman spectroscopic investigations, J. Appl. Phys. 106 (2009) 063513.

[24] Z. Huang, L. Zhang, W. Pan, Synthesis, Lattice Dynamics, and Mechanical Properties of a High-Pressure Scheelite Phase of RVO , Inorg Chem. 51 (2012) 11235-11237.

[25] V. Panchal, D. Errandonea, F. J. Manjon, A. Muñoz, P. Rodriguez-Hernandez, M. Bettinelli, S. N. Achary, A. K. Tyagi, High pressure phase transitions in $\mathrm{NdVO}_{4}$, AIP Conference Proceedings 1665 (2015) 030006.

[26] D. Errandonea, F. J. Manjon, A. Muñoz, P. Rodriguez-Hernandez, V. Panchal, S. N. Achary, A. K. Tyagi, High-pressure polymorphs of $\mathrm{TbVO}_{4}$ : A Raman and $a b$ initio study, J. Alloys Compd. 577 (2013) 327-335. 
[27] V. Panchal, D. Errandonea, A. Segura, P. Rodríguez-Hernandez, A. Muñoz, S. LopezMoreno, and M. Bettinelli, The electronic structure of zircon-type orthovanadates: Effects of high-pressure and cation substitution, J. App. Phys. 110 (2011) 043723.

[28] B. C. Chakoumakos, M. M. Abraham, L. A. Boatner, Crystal Structure Refinements of Zircon-Type $M \mathrm{VO}_{4}(M=\mathrm{Sc}, \mathrm{Y}, \mathrm{Ce}, \mathrm{Pr}, \mathrm{Nd}, \mathrm{Tb}, \mathrm{Ho}, \mathrm{Er}, \mathrm{Tm}, \mathrm{Yb}, \mathrm{Lu})$, J. Solid State Chem. 109 (1994) 197-202.

[29] S. Klotz, L. Paumier, G. Le Marchand, and P. Munsch, Hydrostatic limits of 11 pressure transmitting media, J. Phys. D: Appl. Phys. 42 (2009) 075413.

[30] D. Errandonea, Y. Meng, M. Somayazulu, and D. Häusermann, Pressure-induced $\alpha \rightarrow \omega$ transition in titanium metal: a systematic study of the effects of uniaxial stress, Physica B 355 (2005) 116-125.

[31] H. K. Mao, J. Xu, and P. M. Bell, Calibration of the RubyPressure Gauge to 800 kbar Under Quasi-Hydrostatic Conditions, J. Geophys. Res. 91 (1986) 4673-4676.

[32] D. Errandonea, Exploring the properties of $\mathrm{MTO}_{4}$ compounds using high-pressure powder X-ray diffraction, Cryst. Res. Technol. 50 (2015) 729-736.

[33] G. Kresse, J. Furthmuller, Efficient iterative schemes for ab initio total-energy calculations using a plane-wave basis set, Phys. Rev. B 54 (1996) 11169.

[34] C.J. Pickard, B. Winkler, R.K. Chen, M.C. Payne, M.H. Lee, J.S. Lin, J.A. White, V. Milman, D. Vanderbilt, Structural Properties of Lanthanide and Actinide Compounds within the Plane Wave Pseudopotential Approach, Phys. Rev. Lett. 85 (2000) 5122.

[35] J.P. Perdew, K. Burke, M. Ernzerhof, Generalized Gradient Approximation Made Simple, Phys. Rev. Lett. 77 (1996) 3865. 
[36] A. Mujica, A. Rubio, A. Muñoz, R.J. Needs, High-pressure phases of group-IV, III-V, and II-VI compounds, Rev. Mod. Phys. 75 (2003) 863.

[37] K. Parlinski, computer code PHONON. <http://wolf.ifj.edu.pl/phonon/>.

[38] C. Cazorla and J. Iñiguez, Insights into the phase diagram of bismuth ferrite from quasiharmonic free-energy calculations, Phys. Rev. B 88 (2013) 214430.

[39] C, Cazorla and J. Boronat, First-principles modeling of quantum nuclear effects and atomic interactions in solid $\mathrm{He}^{4}$ at high pressure, Phys. Rev. B 91(2015) 024103.

[40] R. J. Angel, Equations of State, Reviews in Mineral. Geochem. 41 (2000) 35-60.

[41] A.-D. Nguyen, K. Murdoch, N. Edelstein, L. A. Boatner, and M. M. Abraham, Polarization dependence of phonon and electronic Raman intensities in $\mathrm{PrVO}_{4}$ and $\mathrm{NdVO}_{4}$, Phys. Rev. B 56 (1997) 7974.

[42] I. Guedes, Y. Hirano, M. Grimsditch, N. Wakabayashi, C. K. Loong, L. A. Boatner, Raman study of phonon modes in $\mathrm{ErVO}_{4}$ single crystals, J. Appl. Phys. 90 (2001) 1843.

[43] V. Panchal, S. Lopez-Moreno, D. Santamarı-Perez, D. Errandonea, F. J. Manjon, P. Rodriguez-Hernandez, A. Muñoz, S. N. Achary, A. K. Tyagi, Zircon to monazite phase transition in $\mathrm{CeVO}_{4}$ : X-ray diffraction and Raman-scattering measurements, Phys. Rev. B 84 (2011) 024111.

[44] R. Lacomba-Perales, D. Errandonea, Y. Meng, M. Bettinelli, High-pressure stability and compressibility of $\mathrm{APO}_{4}(\mathrm{~A}=\mathrm{La}, \mathrm{Nd}, \mathrm{Eu}, \mathrm{Gd}, \mathrm{Er}$, and Y) orthophosphates: An x-ray diffraction study using synchrotron radiation, Phys. Rev. B 81 (2010) 064113.

[45] G. M. Begun, G. W. Beall, A. Boatner, W. J. Gregor, Raman spectra of the rare earth orthophosphates, J. Raman Spectr. 11 (1981) 273-278. 
[46] D. Errandonea, A. Muñoz, P. Rodríguez-Hernández, J. E. Proctor, F. Sapiña, M. Bettinelli, Theoretical and Experimental Study of the Crystal Structures, Lattice Vibrations, and Band Structures of Monazite-Type $\mathrm{PbCrO}_{4}, \mathrm{PbSeO}_{4}, \mathrm{SrCrO}_{4}$, and $\mathrm{SrSeO}_{4}$, Inorg. Chem. 54 (2015) $7524-7535$.

[47] M.T. Dove, Theory of displacive phase transitions in minerals, Am. Mineral. 82 (1997) 213244.

[48] E. Bandiello, D. Errandonea, D. Martinez-Garcia, D. Santamaria-Perez, F.J. Manjón, Effects of high-pressure on the structural, vibrational, and electronic properties of monazite-type $\mathrm{PbCrO}_{4}$, Phys. Rev. B 85 (2012) 024108.

[49] D. Errandonea, J. Pellicer-Porres, D. Martínez-Garcia, J. Ruiz-Fuertes, A. Friedrich, W. Morgenroth, C. Popescu, P. Rodriguez-Hernandez, A. Muñoz, M. Bettinelli, Phase Stability of Lanthanum Orthovanadate at High Pressure, J. Phys. Chem. C 120 (2016) 13749-13762.

[50] D. Errandonea, J. Pellicer-Porres, M.C. Pujol, J. J. Carvajal, M. Aguiló, Room-temperature vibrational properties of potassium gadolinium double tungstate under compression up to 32 GPa, J. Alloys Compd. 638 (2015) 14-20.

[51] D. Errandonea, J. Pellicer-Porres, F. J. Manjón, A. Segura, Ch. Ferrer-Roca, R. S. Kumar, O. Tschauner, J. López-Solano, P. Rodríguez-Hernández, S. Radescu, A. Mujica, A. Muñoz, G. Aquilanti, Determination of the high-pressure crystal structure of $\mathrm{BaWO}_{4}$ and $\mathrm{PbWO}_{4}$, Phys. Rev. B 73 (2006) 224103.

[52] O. Gomis, J. A. Sans, R. Lacomba-Perales, D. Errandonea, Y. Meng, J. C. Chervin, A. Polian, Complex high-pressure polymorphism of barium tungstate, Phys. Rev. B 86 (2012) 054121. 
[53] D. Errandonea, L. Gracia, R. Lacomba-Perales, A. Polian, and J. C. Chervin, Compression of scheelite-type $\mathrm{SrMoO}_{4}$ under quasi-hydrostatic conditions: Redefining the high-pressure structural sequence, J. Appl. Phys. 113 (2013) 123510.

[54] F. J. Manjón, D. Errandonea, N. Garro, J. Pellicer-Porres, P. Rodríguez-Hernández, S. Radescu, J. López-Solano, A. Mujica, A. Muñoz, Lattice dynamics study of scheelite tungstates under high pressure I. BaWO 4 , Phys. Rev. B 74 (2006) 144111.

[55] F. J. Manjón, D. Errandonea, N. Garro, J. Pellicer-Porres, P. Rodríguez-Hernández, S. Radescu, J. López-Solano, A. Mujica, A. Muñoz, Lattice dynamics study of scheelite tungstates under high pressure II. PbWO 4 , Phys. Rev. B 74 (2006) 144112.

[56] D. Errandonea, R. Lacomba-Perales, K.K. Mishra, A. Polian, In-situ high-pressure Raman scattering studies in $\mathrm{PbWO}_{4}$ up to 48 GPa, J. Alloys Compd. 667 (2016) 36-43. 
Table 1: Ab initio calculated and experimental frequencies at ambient conditions, pressure coefficients, and Grüneisen parameters in zircon-type $\mathrm{NdVO}_{4}$.

\begin{tabular}{|c|c|c|c|c|c|c|}
\hline \multirow{2}{*}{$\begin{array}{c}\text { Raman } \\
\text { Mode } \\
\text { Symmetry }\end{array}$} & \multicolumn{3}{|c|}{ Experiment } & \multicolumn{3}{|c|}{ Theory } \\
\hline & $\begin{array}{c}\omega_{0} \\
{\left[\mathrm{~cm}^{-1}\right]}\end{array}$ & $\begin{array}{c}\mathrm{d} \omega / \mathrm{dP} \\
{\left[\mathrm{cm}^{-1} / \mathrm{GPa}\right]}\end{array}$ & $\gamma$ & $\begin{array}{c}\omega_{0} \\
{\left[\mathrm{~cm}^{-1}\right]}\end{array}$ & $\begin{array}{c}\mathrm{d} \omega / \mathrm{dP} \\
{\left[\mathrm{cm}^{-1} / \mathrm{GPa}\right]}\end{array}$ & $\gamma$ \\
\hline $\mathrm{T}\left(\mathrm{E}_{\mathrm{g}}\right)$ & 113.0 & 0.26 & 0.34 & 112.1 & 0.86 & 1.14 \\
\hline $\mathrm{T}\left(\mathrm{B}_{1 \mathrm{~g}}\right)$ & 123.8 & 0.64 & 0.77 & 122.3 & 0.93 & 1.13 \\
\hline $\mathrm{T}\left(\mathrm{E}_{\mathrm{g}}\right)$ & 151.1 & 0.44 & 0.43 & 149.7 & 0.27 & 0.27 \\
\hline $\mathrm{R}\left(\mathrm{E}_{\mathrm{g}}\right)$ & ----- & ----- & -- & 224.6 & 5.22 & 3.44 \\
\hline $\mathrm{T}\left(\mathrm{B}_{1 \mathrm{~g}}\right)$ & 243.1 & 2.66 & 1.62 & 233.9 & 2.95 & 1.87 \\
\hline$v_{2}\left(B_{2 g}\right)$ & 260.9 & -1.32 & -0.75 & 258.2 & -1.59 & -0.91 \\
\hline$v_{4}\left(E_{g}\right)$ & 373.4 & 2.10 & 0.83 & 363.9 & 1.61 & 0.65 \\
\hline$v_{2}\left(A_{1 g}\right)$ & 381.9 & 1.76 & 0.68 & 365.5 & 1.80 & 0.73 \\
\hline$v_{4}\left(B_{1 g}\right)$ & 472.2 & 2.31 & 0.72 & 453.0 & 2.62 & 0.86 \\
\hline$v_{3}\left(B_{1 g}\right)$ & 794.6 & 5.42 & 1.01 & 797.0 & 6.30 & 1.17 \\
\hline$v_{3}\left(E_{g}\right)$ & 808.1 & 4.95 & 0.91 & 801.9 & 5.75 & 1.06 \\
\hline$v_{1}\left(A_{1 g}\right)$ & 871.1 & 5.63 & 0.96 & 859.0 & 6.35 & 1.09 \\
\hline
\end{tabular}


Table 2: Crystal structure of monazite-type $\mathrm{NdVO}_{4}$ calculated at $9.8 \mathrm{GPa}$ (space group P2 $1 / \mathrm{n}$ ). The Wyckoff positions of different atoms are indicated between brackets.

\begin{tabular}{cc}
\hline$a$ & $6.8055 \AA$ \\
$b$ & $7.0586 \AA$ \\
$c$ & $6.5404 \AA$ \\
$\beta$ & $104.62^{\circ}$ \\
$\mathrm{Nd}(4 \mathrm{e})$ & $(0.27418,0.15669,0.10826)$ \\
$\mathrm{V}(4 \mathrm{e})$ & $(0.29786,0.16643,0.62062)$ \\
$\mathrm{O}_{1}(4 \mathrm{e})$ & $(0.23940,0.99567,0.42449)$ \\
$\mathrm{O}_{2}(4 \mathrm{e})$ & $(0.38786,0.35221,0.50284)$ \\
$\mathrm{O}_{3}(4 \mathrm{e})$ & $(0.48915,0.11009,0.83547)$ \\
$\mathrm{O}_{4}(4 \mathrm{e})$ & $(0.11121,0.22502,0.74158)$ \\
\hline
\end{tabular}


Table 3: $A b$ initio calculated frequencies (at $7.3 \mathrm{GPa}$ ) and experimental frequencies (at 6.4 $\mathrm{GPa}$ ), pressure coefficients, and Grüneisen parameters in monazite-type $\mathrm{NdVO}_{4}$.

\begin{tabular}{|c|c|c|c|c|c|c|}
\hline \multirow{2}{*}{$\begin{array}{l}\text { Raman Mode } \\
\text { Symmetry }\end{array}$} & \multicolumn{3}{|c|}{ Experiment } & \multicolumn{3}{|c|}{ Theory } \\
\hline & $\begin{array}{c}\omega \\
{\left[\mathrm{cm}^{-1}\right]}\end{array}$ & $\begin{array}{c}\mathrm{d} \omega / \mathrm{dP} \\
{\left[\mathrm{cm}^{-1} / \mathrm{GPa}\right]}\end{array}$ & $\gamma$ & $\begin{array}{c}\omega \\
{\left[\mathrm{cm}^{-1}\right]}\end{array}$ & $\begin{array}{c}\mathrm{d} \omega / \mathrm{dP} \\
{\left[\mathrm{cm}^{-1} / \mathrm{GPa}\right]}\end{array}$ & $\gamma$ \\
\hline $\mathrm{Bg}$ & 58.0 & 1.00 & 2.41 & 56.5 & 0.21 & 0.52 \\
\hline $\mathrm{Ag}$ & 76.1 & 0.29 & 0.53 & 74.3 & 0.29 & 0.55 \\
\hline $\mathrm{Bg}$ & ---- & ---- & ---- & 95.7 & -0.55 & -0.80 \\
\hline $\mathrm{Ag}$ & 95.9 & -0.28 & -0.41 & 97.2 & -0.27 & -0.39 \\
\hline $\mathrm{Ag}$ & 113.1 & 0.25 & 0.31 & 112.5 & 0.38 & 0.47 \\
\hline $\mathrm{Bg}$ & ---- & ---- & ---- & 128.5 & 0.75 & 0.82 \\
\hline $\mathrm{Bg}$ & ---- & ---- & ---- & 129.8 & 1.42 & 1.53 \\
\hline $\mathrm{Ag}$ & 139.2 & -0.55 & -0.55 & 140.7 & -0.37 & -0.37 \\
\hline $\mathrm{Ag}$ & 144.1 & 0.86 & 0.84 & 156.3 & 1.00 & 0.90 \\
\hline $\mathrm{Bg}$ & 158.6 & 2.10 & 1.85 & 168.2 & 1.89 & 1.57 \\
\hline $\mathrm{Ag}$ & ---- & ---- & ---- & 176.6 & 1.13 & 0.90 \\
\hline $\mathrm{Ag}$ & 190.3 & 2.66 & 1.96 & 205.5 & 2.52 & 1.72 \\
\hline $\mathrm{Bg}$ & ---- & ---- & ---- & 209.6 & 2.19 & 1.46 \\
\hline $\mathrm{Bg}$ & 226.6 & 1.59 & 0.98 & 232.1 & 1.63 & 0.98 \\
\hline $\mathrm{Bg}$ & ---- & ---- & ---- & 247.6 & 2.45 & 1.39 \\
\hline $\mathrm{Ag}$ & ---- & ---- & ---- & 255.4 & 1.47 & 0.81 \\
\hline $\mathrm{Bg}$ & 263.2 & 2.77 & 1.47 & 263.6 & 2.84 & 1.51 \\
\hline $\mathrm{Ag}$ & 291.4 & 2.37 & 1.14 & 279.1 & 2.96 & 1.48 \\
\hline $\mathrm{Bg}$ & 310.6 & 2.39 & 1.08 & 305.5 & 1.89 & 0.87 \\
\hline $\mathrm{Ag}$ & ---- & ---- & ---- & 328.7 & 1.00 & 0.43 \\
\hline $\mathrm{Bg}$ & ---- & ---- & ---- & 336.2 & 2.09 & 0.87 \\
\hline $\mathrm{Ag}$ & 362.2 & 3.44 & 1.33 & 356.9 & 2.68 & 1.05 \\
\hline $\mathrm{Ag}$ & 378.8 & 3.75 & 1.39 & 382.3 & 3.67 & 1.34 \\
\hline $\mathrm{Ag}$ & 399.4 & 4.03 & 1.41 & 406.0 & 3.19 & 1.10 \\
\hline $\mathrm{Bg}$ & ---- & ---- & ---- & 412.4 & 2.49 & 0.85 \\
\hline $\mathrm{Bg}$ & 427.7 & 3.58 & 1.17 & 424.5 & 2.21 & 0.73 \\
\hline $\mathrm{Ag}$ & ---- & ---- & ---- & 444.5 & 2.78 & 0.88 \\
\hline $\mathrm{Bg}$ & 459.2 & 3.41 & 1.04 & 456.6 & 3.77 & 1.16 \\
\hline $\mathrm{Ag}$ & 762.9 & 5.49 & 1.01 & 788.8 & 3.59 & 0.64 \\
\hline $\mathrm{Bg}$ & ---- & ---- & ---- & 804.2 & 3.51 & 0.61 \\
\hline $\mathrm{Ag}$ & 822.3 & 3.88 & 0.66 & 817.6 & 4.23 & 0.72 \\
\hline $\mathrm{Ag}$ & 854.7 & 3.32 & 0.54 & 850.2 & 2.26 & 0.37 \\
\hline $\mathrm{Bg}$ & ---- & ---- & ---- & 861.5 & 4.69 & 0.76 \\
\hline $\mathrm{Ag}$ & ---- & ---- & ---- & 881.9 & 3.72 & 0.59 \\
\hline $\mathrm{Bg}$ & ---- & ---- & ---- & 882.6 & 3.40 & 0.54 \\
\hline $\mathrm{Bg}$ & 890.9 & 2.54 & 0.40 & 902.7 & 2.41 & 0.37 \\
\hline
\end{tabular}


Table 4: Crystal structure of $\mathrm{BaWO}_{4}$-II-type $\mathrm{NdVO}_{4}$ calculated at $15.8 \mathrm{GPa}$ (space group $\left.\mathrm{P} 2{ }_{1} / \mathrm{n}\right)$. The Wyckoff positions of different atoms are indicated between brackets.

\begin{tabular}{cc}
\hline$a$ & $12.3630 \AA$ \\
$b$ & $6.4442 \AA$ \\
$c$ & $6.8174 \AA$ \\
$\beta$ & $96.16^{\circ}$ \\
$\mathrm{Nd}_{1}(4 \mathrm{e})$ & $(0 . .89292,0.83968,0.11759)$ \\
$\mathrm{Nd}_{2}(4 \mathrm{e})$ & $(0.87508,0.55366,0.63608)$ \\
$\mathrm{V}_{1}(4 \mathrm{e})$ & $(0.87160,0.32781,0.17440)$ \\
$\mathrm{V}_{2}(4 \mathrm{e})$ & $(0.83104,0.05367,0.60301)$ \\
$\mathrm{O}_{1}(4 \mathrm{e})$ & $(0.93827,0.53816,0.32154)$ \\
$\mathrm{O}_{2}(4 \mathrm{e})$ & $(0.79256,0.86204,0.77774)$ \\
$\mathrm{O}_{3}(4 \mathrm{e})$ & $(0.90259,0.89948,0.46801)$ \\
$\mathrm{O}_{4}(4 \mathrm{e})$ & $(0.77872,0.13698,0.08896)$ \\
$\mathrm{O}_{5}(4 \mathrm{e})$ & $(0.91798,0.19443,0.75993)$ \\
$\mathrm{O}_{6}(4 \mathrm{e})$ & $(0.80881,0.27289,0.41770)$ \\
$\mathrm{O}_{7}(4 \mathrm{e})$ & $(0.98972,0.19608,0.14742)$ \\
$\mathrm{O}_{8}(4 \mathrm{e})$ & $(0.5469,0.51500,0.98392)$ \\
\hline
\end{tabular}


Table 5: Ab initio calculated frequencies, pressure coefficients, and Grüneisen parameters in $\mathrm{BaWO}_{4}$-II-type $\mathrm{NdVO}_{4}$ at $15.8 \mathrm{GPa}$.

\begin{tabular}{|c|c|c|c|c|c|c|c|}
\hline $\begin{array}{l}\text { Raman Mode } \\
\text { Symmetry }\end{array}$ & $\begin{array}{c}\omega \\
{\left[\mathrm{cm}^{-1}\right]}\end{array}$ & $\begin{array}{c}\mathrm{d} \omega / \mathrm{dP} \\
{\left[\mathrm{cm}^{-1} / \mathrm{GPa}\right]}\end{array}$ & $\gamma$ & $\begin{array}{l}\text { Raman } \\
\text { Mode } \\
\text { Symmetry }\end{array}$ & $\begin{array}{c}\omega \\
{\left[\mathrm{cm}^{-1}\right]}\end{array}$ & $\begin{array}{c}\mathrm{d} \omega / \mathrm{dP} \\
{\left[\mathrm{cm}^{-1 / G P a}\right]}\end{array}$ & $\gamma$ \\
\hline $\mathrm{Ag}$ & 82.24 & 1.73 & 3.09 & $\mathrm{Bg}$ & 362.54 & 2.71 & 1.10 \\
\hline $\mathrm{Bg}$ & 82.24 & 1.73 & 3.09 & $\mathrm{Bg}$ & 376.87 & 3.82 & 1.49 \\
\hline $\mathrm{Bg}$ & 90.84 & 0.81 & 1.31 & $\mathrm{Ag}$ & 415.58 & 6.35 & 2.24 \\
\hline $\mathrm{Ag}$ & 100.51 & 0.50 & 0.73 & $\mathrm{Bg}$ & 386.19 & 0.88 & 0.34 \\
\hline $\mathrm{Bg}$ & 110.61 & 1.08 & 1.43 & $\mathrm{Ag}$ & 398.15 & 0.98 & 0.36 \\
\hline $\mathrm{Ag}$ & 106.28 & 0.37 & 0.51 & $\mathrm{Bg}$ & 414.17 & 3.05 & 1.08 \\
\hline $\mathrm{Ag}$ & 140.28 & 2.18 & 2.28 & $\mathrm{Ag}$ & 415.24 & 0.66 & 0.23 \\
\hline $\mathrm{Bg}$ & 134.99 & 0.55 & 0.60 & $\mathrm{Bg}$ & 415.24 & 0.66 & 0.23 \\
\hline $\mathrm{Ag}$ & 150.41 & 3.72 & 3.63 & $\mathrm{Bg}$ & 431.60 & 1.96 & 0.67 \\
\hline $\mathrm{Bg}$ & 146.80 & 2.52 & 2.52 & $\mathrm{Bg}$ & 431.90 & 2.62 & 0.89 \\
\hline $\mathrm{Ag}$ & 146.34 & 0.50 & 0.50 & $\mathrm{Ag}$ & 454.11 & 3.63 & 1.17 \\
\hline $\mathrm{Bg}$ & 168.18 & 2.46 & 2.14 & $\mathrm{Ag}$ & 445.91 & 3.32 & 1.09 \\
\hline $\mathrm{Ag}$ & 163.88 & 1.17 & 1.05 & $\mathrm{Ag}$ & 459.37 & 3.56 & 1.14 \\
\hline $\mathrm{Bg}$ & 189.42 & 2.32 & 1.80 & $\mathrm{Ag}$ & 477.04 & 1.91 & 0.59 \\
\hline $\mathrm{Ag}$ & 187.44 & 2.26 & 1.77 & $\mathrm{Bg}$ & 531.65 & 9.04 & 2.49 \\
\hline $\mathrm{Bg}$ & 201.26 & 3.17 & 2.31 & $\mathrm{Bg}$ & 525.61 & 1.98 & 0.55 \\
\hline $\mathrm{Bg}$ & 240.69 & 5.24 & 3.20 & $\mathrm{Ag}$ & 505.78 & 2.99 & 0.87 \\
\hline $\mathrm{Bg}$ & 218.56 & 0.63 & 0.42 & $\mathrm{Bg}$ & 526.64 & 3.40 & 0.95 \\
\hline $\mathrm{Ag}$ & 259.36 & 6.07 & 3.44 & $\mathrm{Bg}$ & 549.25 & 4.35 & 1.16 \\
\hline $\mathrm{Ag}$ & 244.55 & 3.60 & 2.16 & $\mathrm{Ag}$ & 552.78 & 2.55 & 0.68 \\
\hline $\mathrm{Bg}$ & 245.52 & 2.54 & 1.52 & $\mathrm{Bg}$ & 566.28 & 3.55 & 0.92 \\
\hline $\mathrm{Ag}$ & 242.15 & 1.96 & 1.19 & $\mathrm{Bg}$ & 614.39 & 4.56 & 1.09 \\
\hline $\mathrm{Bg}$ & 278.31 & 6.48 & 3.42 & $\mathrm{Ag}$ & 627.18 & 4.47 & 1.05 \\
\hline $\mathrm{Ag}$ & 265.26 & 2.63 & 1.45 & $\mathrm{Ag}$ & 674.17 & 11.39 & 2.48 \\
\hline $\mathrm{Ag}$ & 266.23 & 1.55 & 0.86 & $\mathrm{Ag}$ & 659.02 & 1.29 & 0.29 \\
\hline $\mathrm{Bg}$ & 277.71 & 3.76 & 1.99 & $\mathrm{Ag}$ & 739.86 & 5.81 & 1.15 \\
\hline $\mathrm{Ag}$ & 285.60 & 5.14 & 2.64 & $\mathrm{Bg}$ & 734.84 & 5.14 & 1.03 \\
\hline $\mathrm{Bg}$ & 277.70 & 1.52 & 0.81 & $\mathrm{Bg}$ & 747.72 & 4.88 & 0.96 \\
\hline $\mathrm{Bg}$ & 283.78 & 2.82 & 1.46 & $\mathrm{Ag}$ & 796.29 & 2.42 & 0.45 \\
\hline $\mathrm{Ag}$ & 305.11 & 5.19 & 2.50 & $\mathrm{Bg}$ & 825.40 & 3.33 & 0.59 \\
\hline $\mathrm{Ag}$ & 337.85 & 6.29 & 2.73 & $\mathrm{Ag}$ & 841.67 & 3.15 & 0.55 \\
\hline $\mathrm{Ag}$ & 359.39 & 2.36 & 0.96 & $\mathrm{Bg}$ & 864.07 & 3.46 & 0.59 \\
\hline $\mathrm{Bg}$ & 384.55 & 9.29 & 3.55 & $\mathrm{Ag}$ & 871.15 & 4.00 & 0.67 \\
\hline $\mathrm{Ag}$ & 358.63 & 4.39 & 1.80 & $\mathrm{Bg}$ & 879.57 & 4.02 & 0.67 \\
\hline $\mathrm{Bg}$ & 346.16 & 1.69 & 0.72 & $\mathrm{Ag}$ & 937.45 & 3.70 & 0.58 \\
\hline $\mathrm{Ag}$ & 360.79 & 3.47 & 1.41 & $\mathrm{Bg}$ & 945.12 & 3.60 & 0.56 \\
\hline
\end{tabular}




\section{Figure Captions}

Figure 1: Enthalpy as a function of pressure. The zircon structure is taken as a reference.

Figure 2: (a) Raman spectra of zircon-type $\mathrm{NdVO}_{4}$ between 1 atm and $4.9 \mathrm{GPa}$. (b) Experimental (symbols) and theoretical (lines) pressure dependence of the Raman-mode frequencies in zircon-type $\mathrm{NdVO}_{4}$. The dashed lines represent Raman mode not observed in the experiments.

Figure 3: (a) Raman spectra of monazite-type $\mathrm{NdVO}_{4}$ at pressures between $5.9 \mathrm{GPa}$ and 18.1 GPa. (b) Experimental (symbols) and theoretical (lines) pressure dependence of the Raman-mode frequencies in monazite-type $\mathrm{NdVO}_{4}$.

Figure 4: Raman spectra of $\mathrm{NdVO}_{4}$ at pressures between $19 \mathrm{GPa}$ and $30.8 \mathrm{GPa}$. 


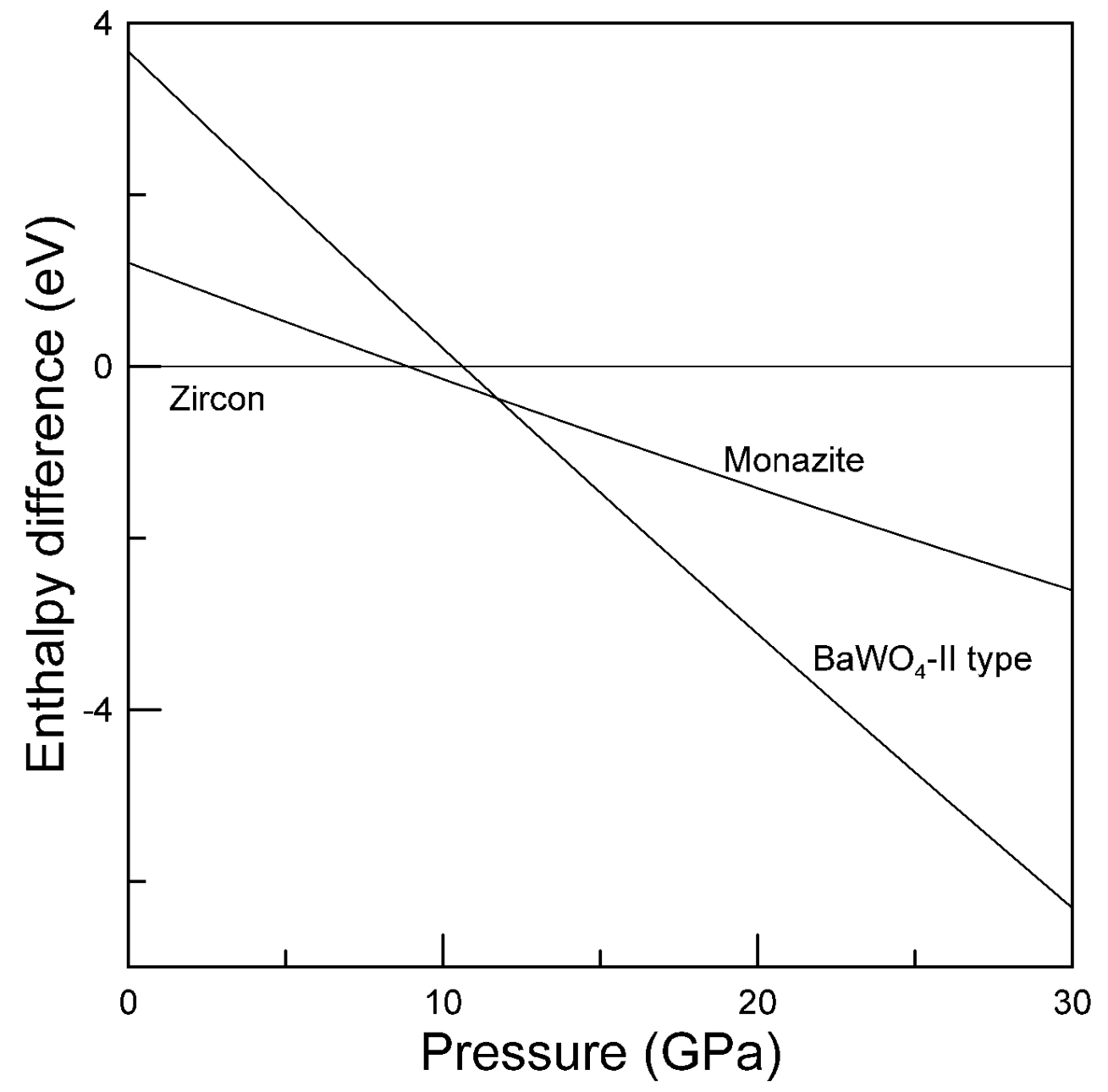

Figure 1 


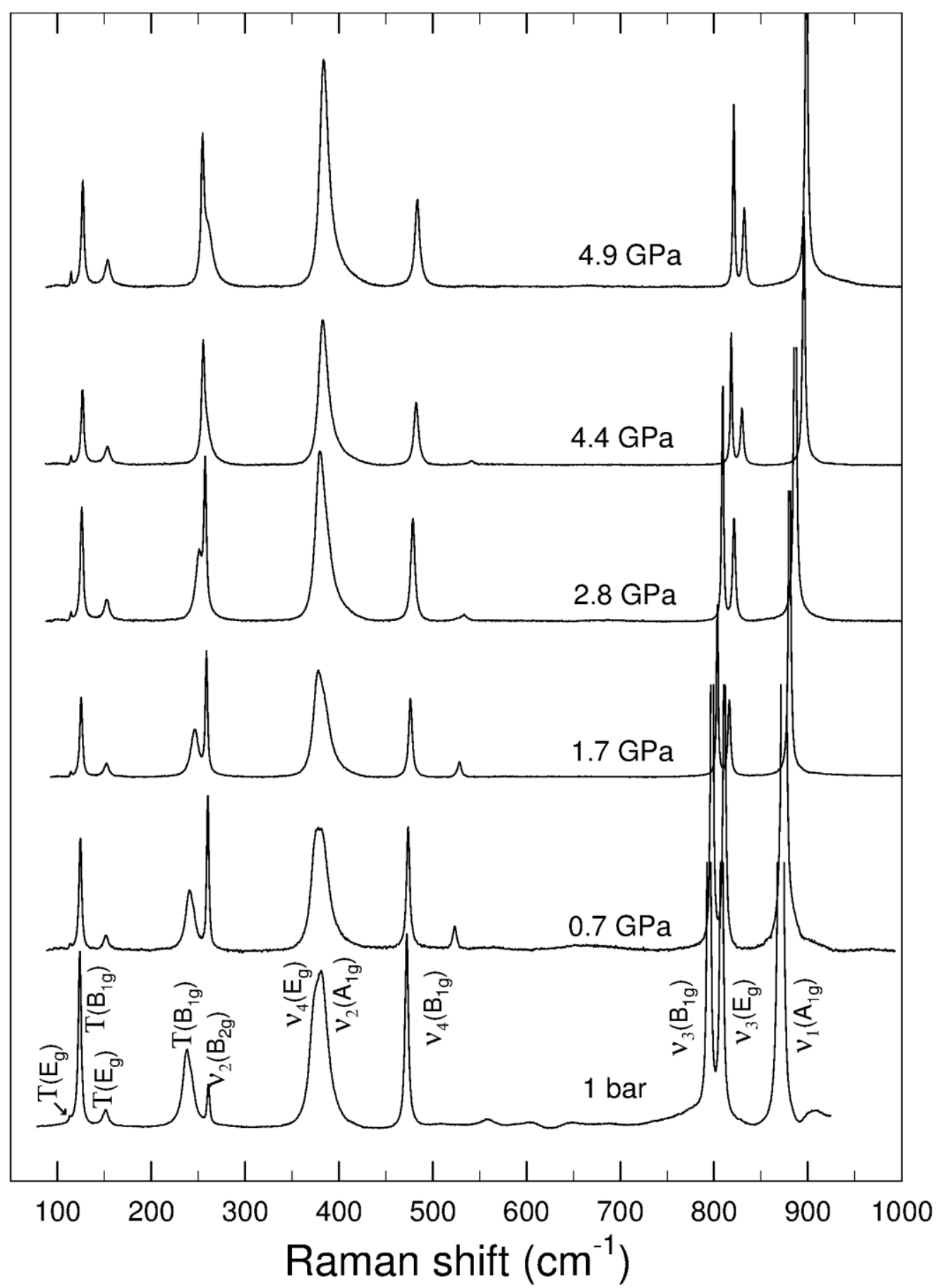

Figure 2(a) 


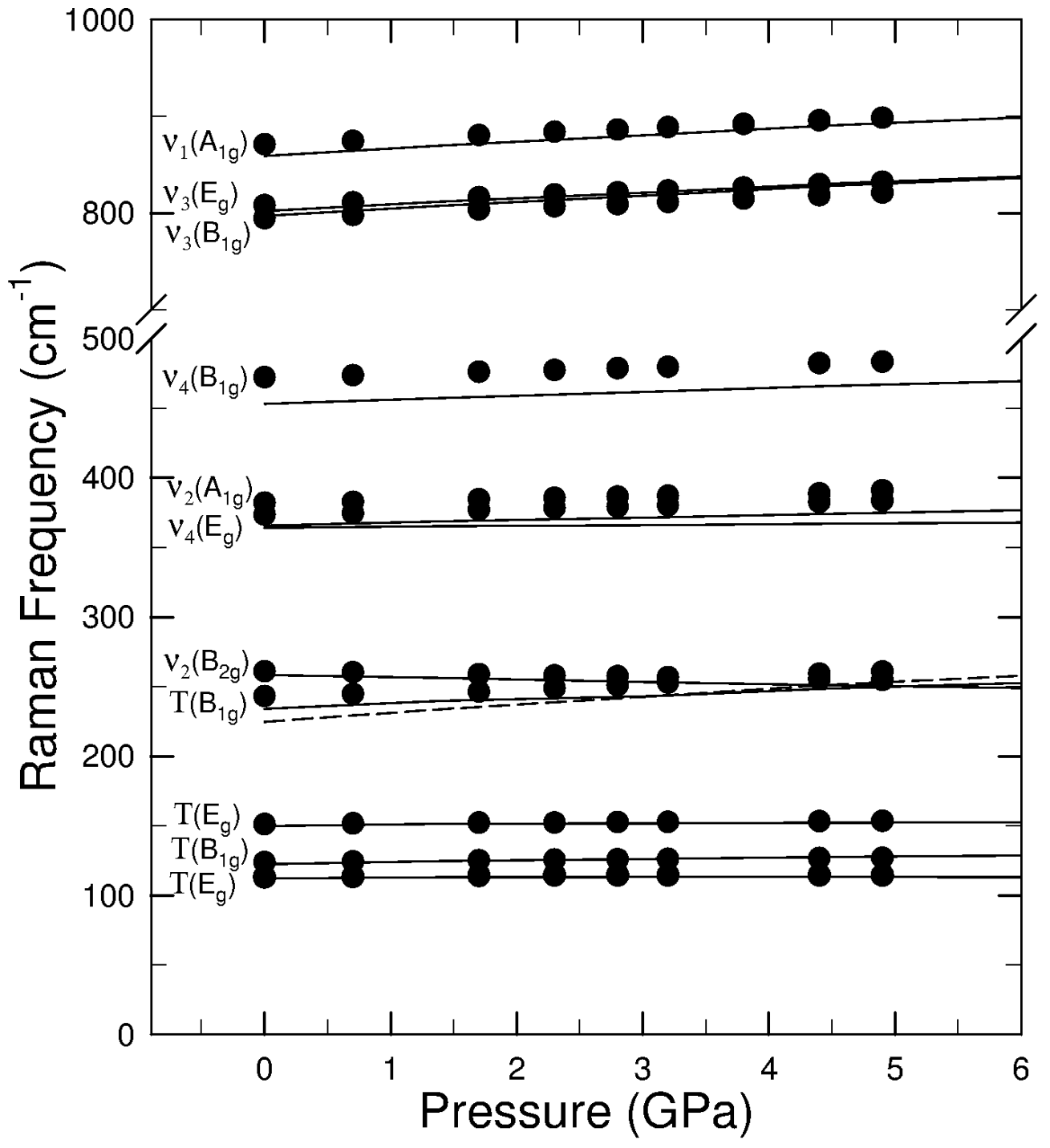

Figure 2(b) 


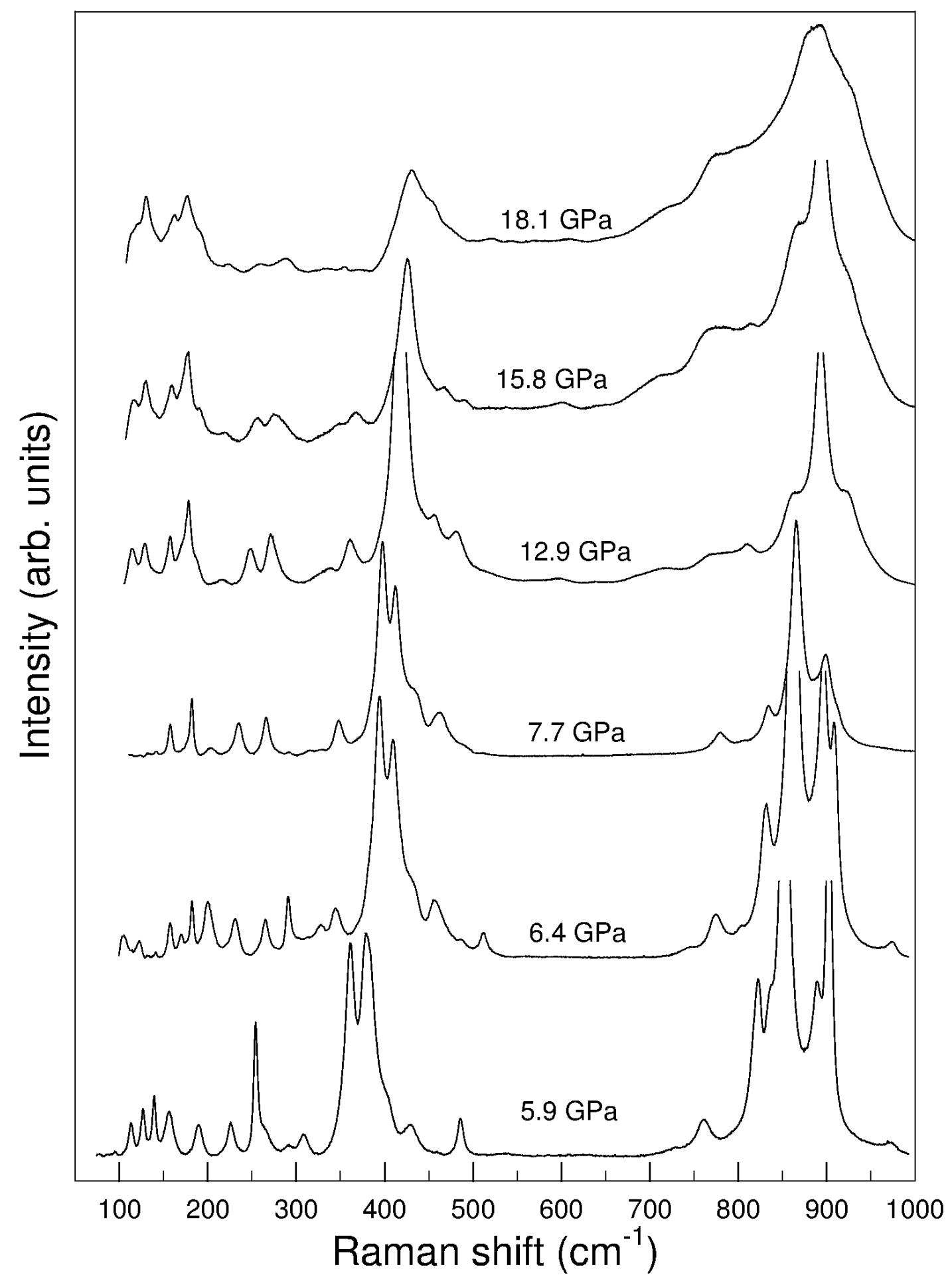

Figure 3(a) 


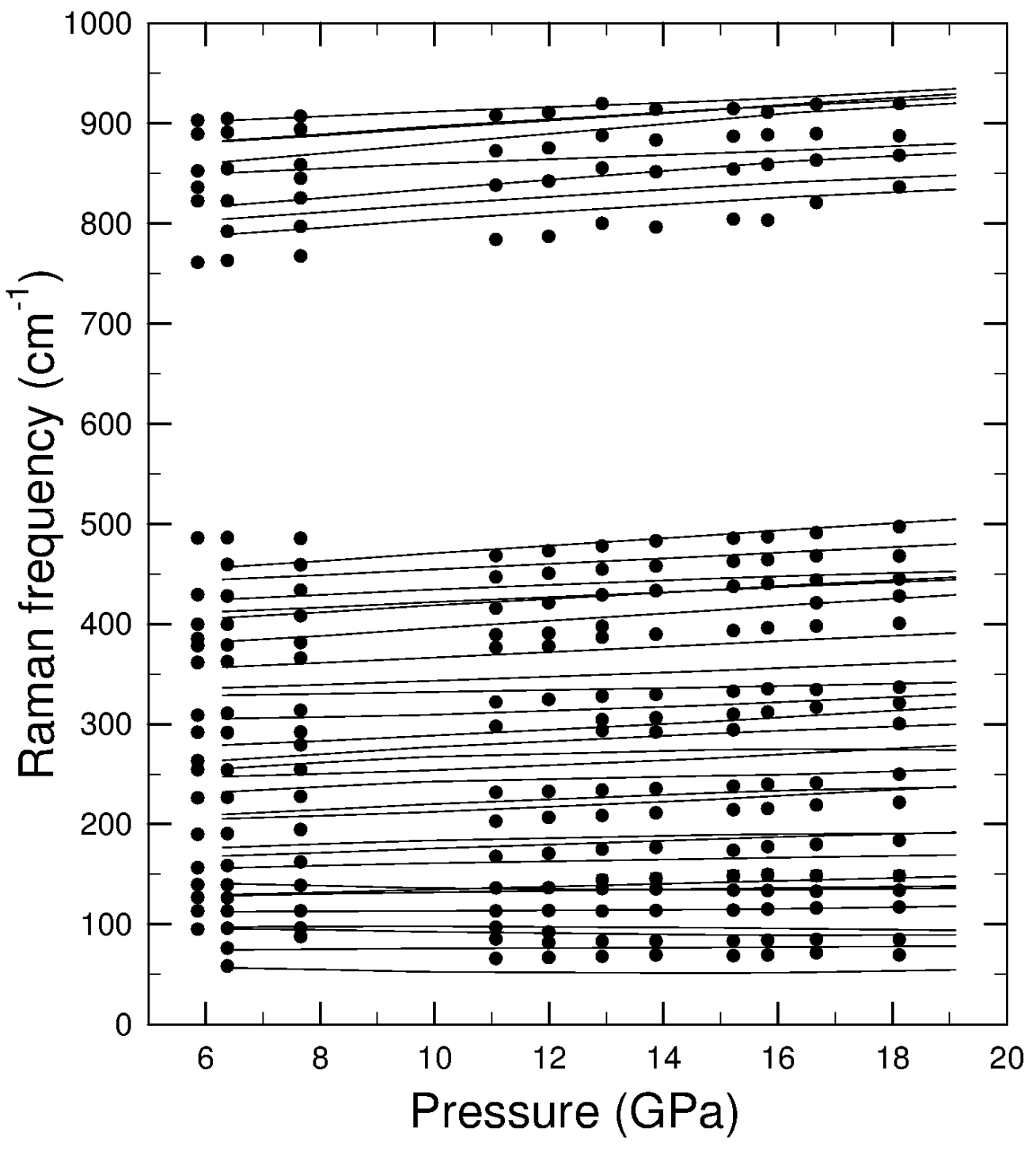

Figure 3(b) 


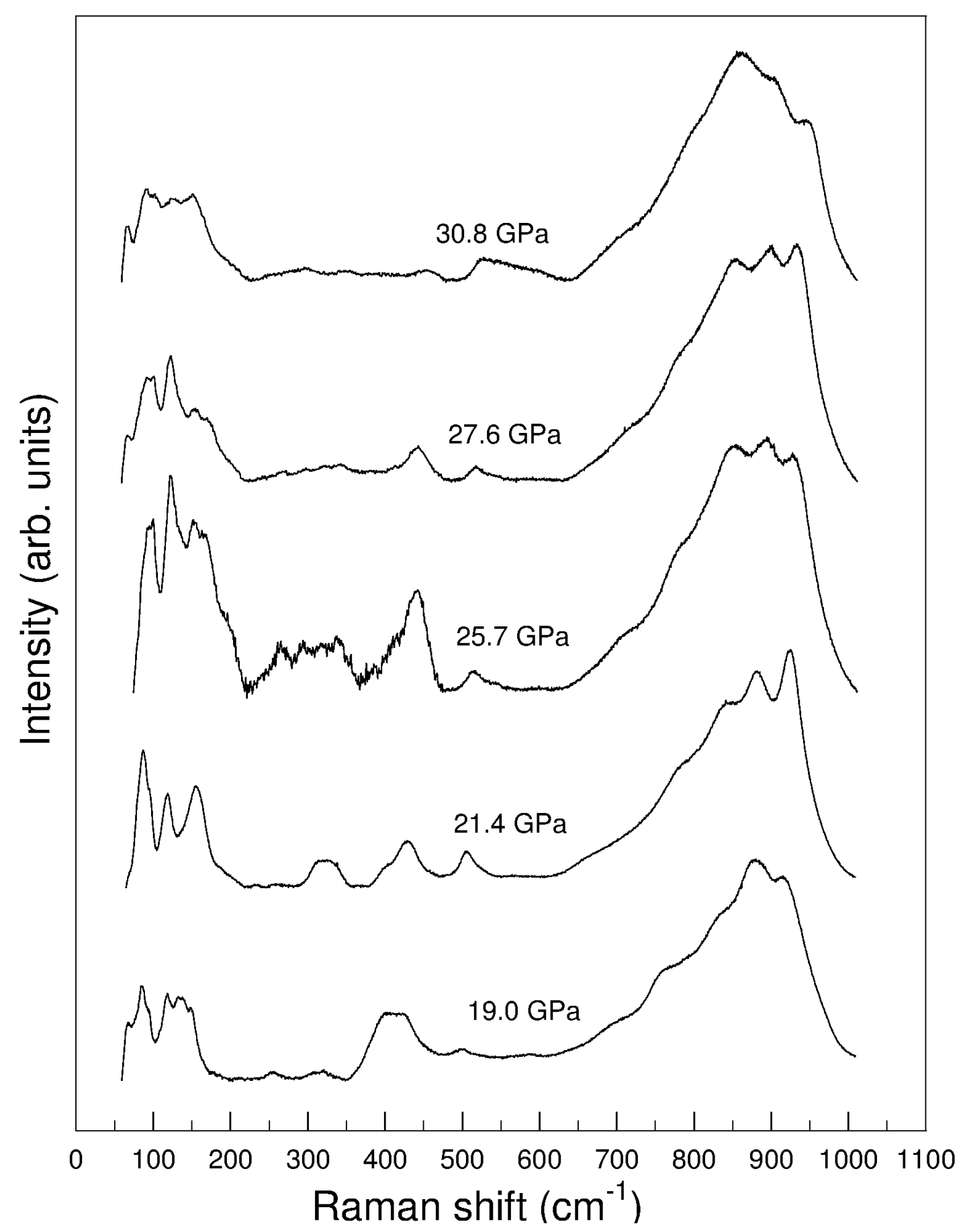

Figure 4 